Daniel Vézina $M D$,

Claude A. Trépanier MD FRCPC, *

Martin R. Lessard MD FRCPC, *

Jean Bussières $M D$ FRCPC $\dagger$

\section{Esophageal and tracheal distortion by the Esophageal-Tracheal Combitube: a cadaver study}

Purpose: To understand the anatomical relationships of the Esophageal-Tracheal Combitube (ETC) with the larynx, pharynx, esophagus and trachea.

Methods: An extensive dissection of the neck and thorax of a 70-yr-old caucasian male cadaver was done to expose the larynx, pharynx, trachea and esophagus. The ETC was inserted following the manufacturer's recommendations. Effects of the ETC on the surrounding structures were observed with the ETC first inserted in the esophagus and then, in the trachea.

Results: When inserted in the esophagus, the ETC produced marked bulging of the anterior wall of the esophagus and anterior displacement $(4.5 \mathrm{~cm})$ of the trachea. Inflation of the distal cuff of the ETC produced distension of the esophagus. When inserted in the trachea, the ETC also caused anterior protrusion.

Conclusion: Protusion of the anterior wall of the esophagus and distension resulting from inflation of the distal cuff could lead to esophageal injuries. These observations may explain the previously reported complications associated with the use of the ETC.

Objectif : Comprendre les relations anatomiques entre le Combitube et le larynx, le pharynx, l'œesophage et la trachée.

Méthode : Une importante dissection du cou et du thorax a été pratiquée sur le cadavre d'un homme de 70 ans de race blanche afin d'exposer le larynx, le pharynx, la trachée et l'œesophage. Une fois le Combitube inséré selon les directives du manufacturier, on en a observé les effets sur les structures environnantes, le tube étant d'abord dans l'œsophage, puis dans la trachée.

Résultats : Quand le Combitube était dans l'œesophage, il a produit un bombement marqué de la paroi antérieure de l'œsophage et un déplacement antérieur de la trachée $(4,5 \mathrm{~cm})$. Le gonflement du ballonnet distal du Combitube a produit une distension de l'œsophage. Inséré dans la trachée, le Combitube a aussi causé une protrusion antérieure.

Conclusion : La protrusion de la paroi antérieure de l'œesophage et la distension qui résultent du gonflement du ballonnet distal peuvent provoquer des lésions à l'œsophage. Ces observations peuvent expliquer les complications déjà connues, associées à l'usage du Combitude.

From the Départements d'anesthésie, Centre hospitalier affilié universitaire de Québec," (Pavillon Enfant- Jésus) and Hôpital Laval, $†$ Université Laval, Québec, Canada.

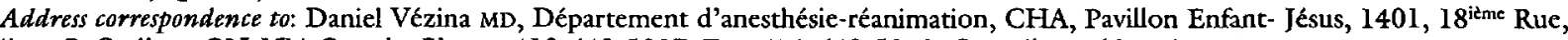
Québec, P. Québec, GlJ 1Z4 Canada. Phone: 418-649-5807; Fax: 418-649-5918; E- mail: vezd@quebectel.com

Accepted for publication January 22, 1999 
$\mathrm{T}$

HE Esophageal-Tracheal Combitube (ETC) (Kendall Sheridan Catheter corp., Argyle, New-York, USA) is gaining popularity for airway management during cardiopulmonary resuscitation (CPR). ${ }^{1-5}$ In recent years, its use has expanded to the management of the airway for trauma patients in a prehospital setting. ${ }^{6}$ The ASA and the Canadian Airway Focus Group have also included the ETC in their difficult airway algorithms. ${ }^{7-8}$ However, two reports of complications associated with the use of the ETC have been recently published. Klein $e t$ al. reported a case of esophageal rupture, which occurred when the ETC was used for airway management during general anesthesia. ${ }^{9}$ We have also reported four cases of subcutaneous emphysema, pneumomediastinum and pneumoperitoneum that occurred during CPR in a prehospital setting. ${ }^{10}$ In the latter, autopsy studies revealed superficial and deep transparietal lacerations of the anterior wall of the esophagus in two cases and superficial lacerations in an other. However, the pathophysiology of these complications is not clearly understood.

The first objective of this study was to understand the anatomical relationships of the ETC and the larynx, pharynx, esophagus and trachea during its insertion. The second objective was to explain the mechanism by which esophageal injury might occur.

\section{Methods}

The study was conducted at the anatomy laboratory of Laval University. The cadaver of a 70 -yr-old caucasian man, deceased six hours before, was used for the study. The subject was $1.78 \mathrm{~m}$ tall, weighed $64 \mathrm{~kg}$ and apparently had no history of esophageal or airway problems. No resuscitative attempts had been made and no airway management device had been used.

With the subject in the supine position, an extensive dissection of the neck exposed the larynx, trachea and all the peripharyngeal structures. The ribs were cut along the anterior axillary line on both sides and both clavicles were resected. Then, the anterior portion of the thoracic cage was removed. The pleural cavities were opened, the right main bronchus was transected and the right lung resected, thus allowing an unobstructed anterolateral view of the intrathoracic portion of the esophagus and the trachea. The left lung was left in place to provide structural support to the mediastinum.

A standard size (4l French) well lubricated ETC was slowly inserted, following the blind insertion technique recommended by the manufacturer, and was advanced until the printed marks on the tube aligned with the incisor teeth. Simultaneously, the effects of the passage of the ETC on the pharynx, larynx, trachea and esophagus were observed. Once the ETC reached its final position in the esophagus, the proximal balloon was inflated with $100 \mathrm{ml}$ air, while closely observing its effect on pharyngeal structures. Then, the distal cuff was inflated in increments of $5 \mathrm{ml}$ air up to $40 \mathrm{ml}$ and again, the effects of the inflation on the esophagus, larynx and trachea were observed.

The ETC was then removed and manually guided into the trachea with the same sequence of observations. Finally, the ETC was removed, the trachea and larynx were resected as a whole and the esophagus was excised from its pharyngeal origin to the cardia. The esophagus was then opened longitudinally along the midline of its posterior wall to allow direct visualization of the mucosa. The same procedure was done for the larynx and trachea. The remaining upper airway was evaluated in situ through an anterior incision. Pictures were taken at all stages of the procedure.

\section{Results}

During blind insertion, the ETC followed the posterior wall of the pharynx, on a path posterior to the larynx and entered the esophagus spontaneously. The distal tip of the ETC produced marked bulging of the anterior wall of the esophagus. This protrusion was even more pronounced when the ETC was pushed further into the esophagus. When the printed marks on the ETC were at level of the incisor teeth, the tip of the ETC lay in a mid-esophageal position and the bulging caused by the ETC produced anterior displacement of the tracheal carina of $4.5 \mathrm{~cm}$ (Figures $1,2)$. When the ETC was inserted into the trachea, bulging of the anterior wall of the trachea was also present although to a lesser degree.

Inflation of the proximal balloon of the ETC produced good stabilization of the tube. A slight bulging of the peripharyngeal soft tissues was observed. On the other hand, inflation of the distal cuff of the ETC produced obvious distension of the esophagus. This was even more evident when the distal cuff was inflated beyond the $15 \mathrm{ml}$ recommended by the manufacturer.

Finally, dissection and examination of the esophagus revealed a superficial anterior longitudinal laceration of the mucosa. The pharynx, larynx and trachea were normal.

\section{Discussion}

The main finding of this study was the alteration of the normal tracheal and esophageal anatomical relationships when the ETC was inserted to its esophageal position. Marked bulging of the anterior wall of the esophagus was caused by the anterior curvature of the 


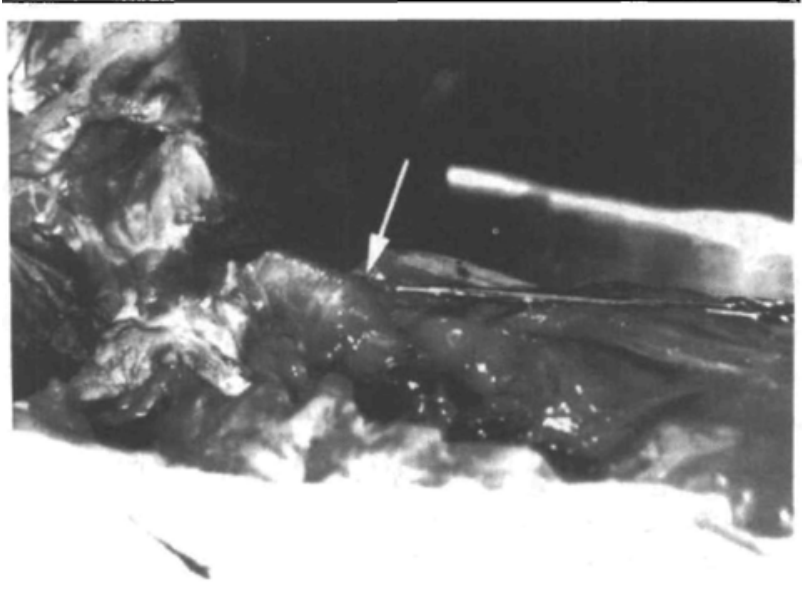

FIGURE I Dissccted cadaver without the Esophageal-Tracheal Combitube. The arrow shows the trachea and the esoplangus at the level of the canina.

ETC. Inflation of the distal cuff of the ETC increased esophageal distension further. When inserted in the trachea, the ETC also caused an anterior protrusion although to a lesser degree than when inserted in the esophagus.

These observations are anatomically compatible with previously reported complications. Four patients presented subcutaneous emphysema following cardiopulmonary resuscitative attempts with the use of the ETC. ${ }^{10}$ At autopsy, some of them showed pharyngeal and esophageal lacerations. In two, large (6 and $6.5 \mathrm{~cm}$ respectively) longitudinal lacerations of the full thickness of the anterior wall of the esophagus were found. These lesions started $3.5 \mathrm{~cm}$ below the pharyngo-esophageal junction, an anatomical location compatible with the hypothesis of direct trauma to the esophageal mucosa by the ETC. The incidence of such esophageal lacerations with the use of the ETC remains unknown.

The ETC is a device developed from the esophageal obturator airway (EOA). The EOA was designed to be inserted blindly without instrumentation as an alternative to tracheal intubation in emergency situations. Although the EOA was usually an effective mean of airway management, it was associated with complications. It was sometimes difficult to produce an effective seal between the mask of the EOA and the face of the patient and, in the situation of inadvertent tracheal placement of the EOA, ventilation was impossible. ${ }^{11-12}$ More important were the cases of esophageal injury and perforation reported with the use of the EOA. ${ }^{13-17}$ The ETC was developed by

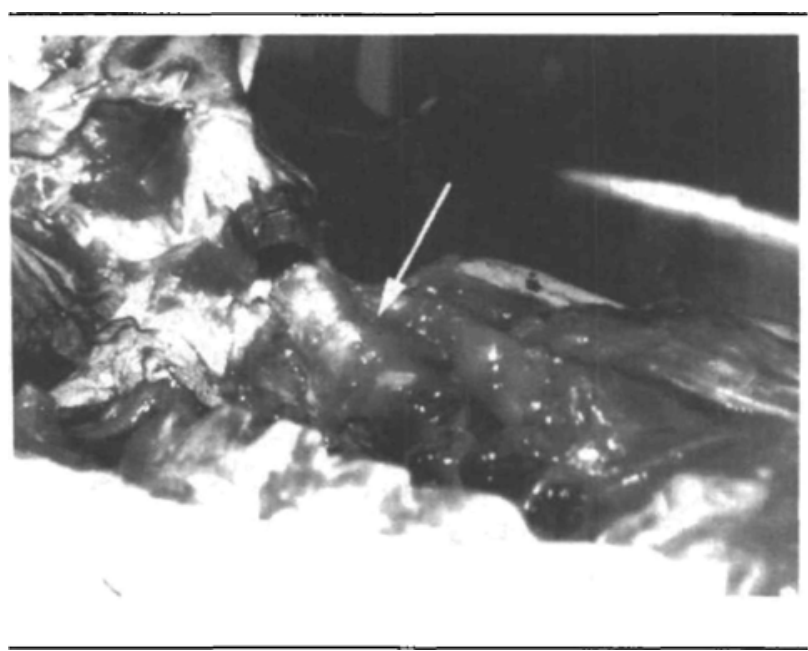

FIGURE 2 Dissected cadaver with the Esophageal-Tracheal Combitube correctly inserted in the esophagus. The arrow shows the anterior displacement of the trachea and the esophagus caused by the ETC.

Frass, Frenzer and Zahler and first reports of its effectiveness and clinical use were published in $1987.3^{3-4}$ The ETC has several differences from the EOA. ${ }^{18}$ It is a stiff tube with a large diameter and a pronounced anterior curvature toward its distal end with a blunt tip. Such a design makes the ETC easy to insert with minimal training. A large volume oropharyngeal balloon effectively seals the upper airway and ventilation is possible whether it is inserted in the esophagus or in the trachea. It is also claimed that its shorter length, compared with the EOA, minimizes the risk of esophageal injury. ${ }^{18}$

The cause and effect relationship between the ETC and the esophageal lacerations and ruptures reported has not been proved. Most cases of esophageal perforation are caused by instrumentation of the esophagus. The observations reported here add more evidence of a direct injury to the esophagus either during the insertion of the ETC or during its use. The size, curvature and stiffness of the ETC caused marked bulging of the anterior wall of the esophagus. Furthermore, despite its curvature, some resistance is felt during its insertion and the operator may not feel the tissue being damaged. In addition, blind insertion of the ETC into the pharynx and the esophagus may favour these injuries, particularly in a stressful emergency situation such as CPR. Overinflation of the distal cuff might also cause injury the esophagus but this was most probably additive to those related to the configuration of the ETC. Finally the possibility that esophageal laceration might be caused by an intraluminal build-up of pressure associated with retching efforts cannot be ruled out. 
Some minor modifications to the ETC could make it less prone to cause esophageal injury. A limiting device for inflation of the distal cuff could be added in order to ensure that the manufacturer's recommendations on balloon inflation volume are respected. A reduced curvature of the distal extremity of the ETC would probably lessen the protrusion of the anterior wall of the esophagus. Softening its extremity could also be considered. However, a critical caveat is the ease of insertion that must be preserved. The ETC is a device intended to be used with minimal training by a variety of health care workers. Any modification to the ETC should be weighed against a possible decrease in ease of insertion.

The methodology of this study has some limitations. First, the study was not performed on a living subject. Second, it was limited to the study of only one cadaver. The observations reported here should be confirmed either in vivo or in a larger sample of cadavers of different heights and weights. Third, although the delay between death and the dissection was only a few hours, some post-mortem rigidity and dryness of the mucosa may have influenced the effect of the ETC on anatomical structures compared to the living patient. This dryness of the mucosa was probably an important contributing factor in the production of the esophageal laceration found in this study. This finding must be interpreted with caution given this limitation. Fourth, the extensive dissection done to allow good exposure of the pharynx, larynx, trachea and esophagus, might have modified the normal anatomical relationships. However, it is doubtful that the marked bulging of the esophagus observed can be attributed solely to these factors.

This study has some clinical implications. The indications for the use of ETC should be limited. In a prehospital CPR setting, the ability to secure the airway rapidly and efficiently is crucial and might be traded off for a low incidence of esophageal injury. This device is also a useful adjunct in the cannot-intubate cannot-ventilate situation. However, in the usual anesthesia setting, an esophageal laceration, even if rare, is a severe complication that must not be ignored. Insertion of the ETC should be a gentle and delicate manoeuvre. As suggested by Frass, the use of a laryngoscope should be considered whenever feasible. ${ }^{18}$ Finally, awareness of the possibility of esophageal damage should lead to a more rapid diagnosis and hopefully a low morbidity and mortality, should it occur.

We conclude that the distal anterior curvature of the ETC causes marked protrusion of the anterior wall of the esophagus and has the potential of causing injuries. Overinflation of the distal cuff also causes marked distension of the esophagus. These observations may explain previously reported complications with the ETC.

\section{References}

1 Atherton GL, Jobnson JC. Ability of paramedics to use the Combitube ${ }^{\mathrm{TM}}$ in prehospital cardiac arrest. Ann Emerg Med 1993; 22: 1263-8.

2 Lefranģois $D$. Défibrillation préhospitalière dans un système non médicalisé. Isis-Urgence Pratique 1995; 12: 15-21.

3 Frass $M$, Frenzer $R$, Zdrabal F, Hofiehner G, Porges $P$, Lackner $F$. The esophageal tracheal Combitude: preliminary results with a new airway for CPR. Ann Emerg Med 1987; 16: 768-72.

4 Frass $M$, Frenzer R, Rauscha F, Weber H, Pacher $R$, Leithner $C$. Evaluation of esophageal tracheal combitube in cardiopulmonary resuscitation. Crit Care Med 1987; 15: 609-11.

5 Frass M, Frenzer R, Rauscha F, Schuster E, Glogar D. Ventilation with the esophageal tracheal combitube in cardiopulmonary resuscitation. Promptness and effectiveness. Chest 1988; 93: 781-4.

6 Blostein PA, Koestner AJ, Hoak S. Failed rapid sequence intubation in trauma patients: esophageal tracheal combitube is a useful adjunct. J Trauma 1998; 44: 534-7.

7 American Society of Anesthesiologist Task Force on Management of The Difficult Airway. Practice guidelines for management of the difficult airway. Anesthesiology 1993; 78: 597-602.

8 Crosby ET, Cooper RM, Douglas MJ, et al. The unanticipated difficult airway with recommendations for management. Can J Anaesth 1998; 45: 757-76.

9 Klein $H$, Williamson M, Sue-Ling HM, Vucevic M, Quinn $A C$. Esophageal rupture associated with the use of the Combitube ${ }^{\mathrm{TM}}$. Anesth Analg 1997; 85: 937-9.

10 Vézina D, Lessard MR, Bussières J, Topping C, Trépanier $C A$. Complications associated with the use of the Esophageal-Tracheal Combitube. Can J Anaesth 1998; 45: 76-80.

11 Bryson TK, Benumof JL, Ward CF. The esophageal obturator airway. A clinical comparison of ventilation with a mask and oropharyngeal airway. Chest 1978; 74: 537-9.

12 Gertler JP, Cameron DE, Shea K, Baker CC. The esophageal obturator airway: obturator or obtundator? J Trauma 1985; 25: 424-5.

13 Strate RG, Fischer RP. Midesophageal perforations by esophageal obturator airways. J Trauma 1976; 16: 503-9.

14 Harrison EE, Nord HJ, Beeman RW. Esophageal perforation following use of the esophageal obturator airway. Ann Emerg Med 1980; 9: 21-5. 
15 Hoffman JR, Pietrafesa CA, Orban DJ. Esophageal perforation following use of esophageal obturator airway (EOA). Am J Emerg Med 1983; 3: 282-7.

16 Scholl DG, Tsai SH. Esophageal perforation following the use of the esophageal obturator airway. Radiology 1977; 122: 315-6.

17 Johnson KR Jr, Genovesi $M G$, Lassar KH. Esophageal obtorator airway: use and complications. JACEP 1976; 5: 36-9.

18 Frass $M$. The Combitube : esophageal/tracheal doublelumen airway. In :Benumof JL (Ed.). Airway

Management, Principles and Practice, $1^{\text {st }}$ ed. St. Louis: Mosby-Year Book Inc., 1996: 446-53. 